\title{
Singleton and twin pregnancies in Red Maradi goats: changes in maternal serum biochemical composition and ovarian biometrics at mid gestation
}

\author{
EDMUND CHIDIEBERE MBEGBU ${ }^{1}$, KENNETH ORJI ANYA², HILLARY EMEKA UGWUANYI', \\ CHUKWUNOMSO EINSTEIN AKANAGA ${ }^{1}$, CLIFFORD NWABUGWU ABIAEZUTE ${ }^{3}$
}

${ }^{1}$ Department of Veterinary Physiology and Pharmacology, ${ }^{2}$ Department of Veterinary Obstetrics and Reproductive Diseases, ${ }^{3}$ Department of Veterinary Anatomy, University of Nigeria, Nsukka, 410001 Nigeria

Mbegbu E. C., Anya K. O., Ugwuanyi H. E., Akanaga C. E., Abiaezute C. N. Singleton and twin pregnancies in Red Maradi goats: changes in maternal serum biochemical composition and ovarian biometrics at mid gestation

\section{Summary}

Pregnancy involves some structural and physiological adjustments to achieve an optimal outcome for the fetus and its mother. The magnitude of these changes is influenced by number of fetuses in utero. This research was designed to compare serum biochemical and ovarian morphometric changes associated with singleton and twin pregnancies in Maradi goats. Using Richardson formula, $2.1 \times[C R L(\mathrm{~cm})+17]$, twelve (12) ovarian and blood samples $(7$ single and 5 twin) from mid gestation $(\approx 70-100$ dGA) pregnant goats were purposively selected. Ovarian weights, ovarian diameters, serum biochemistry and levels of ovarian sex hormones were determined and analyzed using standard procedures. Twin pregnant goats had higher $(p<0.05)$ left ovarian weights, average ovarian weight, left ovarian diameters, average ovarian diameter, serum calcium and inorganic phosphorus levels compared with singleton pregnant goats. There was no significant variation $(p>0.05)$ in the mean crown-rump length, mean gestational age, mean fetal weight, right ovarian weights, right ovarian diameters, serum concentrations of sodium, potassium, chloride, urea, creatinine, AST, ALT, total protein, estrogen and progesterone between sinlgeton and twin pregnant Red Maradi goats. Ovarian sections from the twin bearing mid gestation goats had more growing follicles and fewer primordial follicles compared with the singleton bearing goats. Findings from this study indicate that twin pregnancy, which could be genetically programmed, has the tendency to affect ovarian follicles development, ovarian morphometrics and calcium metabolism in mid gestation in Red Maradi goats.

Keywords: goats, mid gestation, ovary, serum biochemistry, twin pregnancy

Pregnancy is associated with major physiological, hormonal and biochemical alterations aimed at achieving an optimal environment for the fetus and its mother (39). The magnitude of these changes is influenced by the number of developing fetuses (29). Deviation from normal course of pregnancy is assessed by measuring some serum biochemical markers and comparing them with the reference values (8). It is well established that levels of different metabolites and enzymes in serum have implicit connection with physiological processes in goats $(7,43)$, and may be influenced by environmental conditions, reproductive status, and health status $(4,30,35)$.

Domestic goats (Capra aegagrus hircus L.) are important livestock species in developing countries, accounting for up to $90 \%$ of the world's goat population (12). The Maradi goat, also known as the Red Sokoto, belongs to the Savannah goat breed of the Nigerian guinea Savannah agroforest zone (11). They constitute $60 \%$ of the Nigerian goat population of about 34.5 million (23). Goats are multipurpose animals with great economic value and the Maradi goat is particularly valued for its animal protein contribution to humans in the form of meat and milk (17). The distribution of this breed in Nigeria is between latitudes $12^{\circ}$ and $14^{\circ} \mathrm{N}$ and longitudes $4^{\circ}$ and $10^{\circ} \mathrm{E}$; mostly in the northern Nigeria states namely Sokoto, Zamfara, Kano, Kebbi and Katsina States (41). The breed emigrated from the Middle East through Egypt to its present location (41). It is a small sized breed of goat of about $60 \mathrm{~cm}$ height at the withers, and about 25-27 kg weight (33).

Capra hircus are generally known to be both monotocous and polytocous (27). Twinning in goats as well as other domestic ruminants has a genetic un- 
dertone, regulated through induction of insulin-like growth Factor-I (IGF-I) and insulin-like growth factor binding protein-3 (IGFBP-3), with consequent increase in the rate of folliculogenesis and eventual ovulation (26). Specifically, IGF-I gene influences reproductive process by stimulating ovarian activity, (28) and regulating female reproductive hormones like progesterone, estrogen and gonadotropins (18). This means that the IGF-I stimulates the anterior pituitary for secretion of LH which regulates reproductive activity in mammals (9). It has also been documented that mutation in the promoter region of the genes related to litter size may affect ovulation rate in goats, resulting in a corresponding change in prolificacy in small ruminants $(3,16)$.

From the foregoing, it is evident that multiple pregnancies, which could be linked to genetically determined ovarian activity (26), create additional physiologic demands, with attendant homeostatic adjustments in order to ensure the survival of both the dam and the fetuses (29). The aim of the study was to ascertain the comparative serum biochemical and ovarian structural changes associated with singleton and twin pregnancies in Red Maradi goats.

\section{Material and methods}

Sample collection. Twenty-two ovaries $(9$ singles and 13 twins) were promptly harvested from apparently healthy pregnant Maradi goats of average age $(2-<3$ years), presumptuously presented for slaughter at Nsukka Municipal Abattoir, Ikpa, Nsukka Local Government Area, Enugu State, Nigeria between January and February 2019. Blood was collected through the jugular vein into plain bottles for serum biochemistry. The samples collected were immediately transported to the Laboratory Unit of the Department of Veterinary Anatomy, Faculty of Veterinary Medicine, University of Nigeria, Nsukka where the samples were processed. The ovaries were carefully trimmed of adnexa and weighed using an electronic weighing balance (Metler ${ }^{\mathbb{B}}$ Toledo, Switzerland). The longitudinal diameters of the ovaries were determined with the aid of Vernier calipers from its anterior to the posterior end (1). The gestational age was determined using the formula $2.1 \times[\mathrm{CRL}(\mathrm{cm})+17]$ (38). Ultimately, twelve ovarian samples (7 singles and 5 twins) were purposively included in the analysis as mid gestation pregnancies $(\approx 70-100 \mathrm{dGA})$.

Serum biochemistry and hormonal assay. Electrolytes [sodium $(\mathrm{mmol} / \mathrm{L})$, potassium $(\mathrm{mmol} / \mathrm{L})$, chloride $(\mathrm{mmol} / \mathrm{L})$, phosphorus $(\mathrm{mmol} / \mathrm{L})$ and calcium $(\mathrm{mg} / \mathrm{dL})]$ were determined by the colorimetric method. Kidney markers (urea and creatinine concentrations) were determined by kinetic method. Liver markers (ALT and AST) were determined by colorimeter method. The total protein was determined by the direct Biuret method. Serum glucose concentration was estimated using the Beckton Dicknison sugar assay Kit (Becton Dickinson India Pvt. Ltd., Bangalore, India). Estradiol (E2) and progesterone (P4) assay were performed using ELISA Kits (BioCheck, Inc., Foster City, California, USA) and (Monobind Inc., Lake Forest, California, USA) respectively.

Tissue collection and processing for histology. The ovaries were fixed overnight in Bouin's fixative composed of $75 \mathrm{ml}$ saturated aqueous picric acid, $25 \mathrm{ml}$ of formalin ( $40 \%$ formaldehyde) and a few drops of acetic acid. The tissues were successively dehydrated in ascending grades of alcohol; cleared in xylene and infiltrated with molten paraffin wax. The tissues were embedded in a fresh molten paraffin wax to form hard blocks which were mounted on a microtome and serially sectioned at $5 \mu \mathrm{m}$ thick. The tissue sections were mounted on glass slides coated with $20 \%$ albumin, deparaffinised, rehydrated in descending grades of alcohol and stained with haematoxylin and eosin (H\&E). The H\&E stained tissue sections were subsequently dehydrated in ascending grades of alcohol and histoclear II (National Diagnostics, Hessle Hull, England, UK). Finally, the tissue sections were permanently mounted on the microscope glass slides with glass cover slips using DPX (distyrene, plasticizer and xylene) mountant (BDH Laboratory, England, UK) (5).

Statistical analysis. The IBM SPSS statistics version 21.0 for windows (IBM Corp, Armonk, NY, USA) was used for the statistical analyses. Data obtained were statistically analyzed using independent sample student's t-test. The means were considered significant at probability values of $0.05(\mathrm{p}<0.05)$. The results were presented in tables and graphs as means $\pm \mathrm{SD} / \mathrm{SEM}$.

\section{Results and discussion}

Feto-maternal characteristics, liver and kidney markers, and sex steroids concentrations. The mean gestational age (MGA) was calculated by substituting mean crown-rump length (MCRL) of the fetuses in the Richardson formula, and the result showed no significant variation $(p>0.05)$ in the mean crown-rump length (MCRL), mean gestational age (MGA) and mean fetal weight (MFW) between sinlgeton and twin pregnant Red Maradi goats (Tab. 1). There was no significant difference $(p>0.05)$ in the serum AST, ALT, urea,

Tab. 1. Feto-maternal characteristics, serum liver and kidney markers, and sex steroids concentrations

\begin{tabular}{|l|c|c|c|c|c|c|c|c|c|}
\hline \multicolumn{1}{|c|}{ Group } & $\begin{array}{c}\text { MFW } \\
(\mathrm{kg})\end{array}$ & $\begin{array}{c}\text { MCRL } \\
(\mathrm{cm})\end{array}$ & $\begin{array}{c}\text { MGA } \\
(\text { days })\end{array}$ & $\begin{array}{c}\text { AST } \\
(\mathrm{IU} / \mathrm{L})\end{array}$ & $\begin{array}{c}\text { ALT } \\
(\mathrm{IU} / \mathrm{L})\end{array}$ & $\begin{array}{c}\text { Urea } \\
(\mathrm{mg} / \mathrm{dL})\end{array}$ & $\begin{array}{c}\text { Creatinine } \\
(\mathrm{mg} / \mathrm{dL})\end{array}$ & $\begin{array}{c}\mathrm{E}_{2} \\
(\mathrm{pg} / \mathrm{mL})\end{array}$ & $\begin{array}{c}\mathrm{P}_{4} \\
(\mathrm{ng} / \mathrm{mL})\end{array}$ \\
\hline Single & $\mathbf{0 . 6 1} \pm \mathbf{0 . 1 0}$ & $27.87 \pm 2.29$ & $94.23 \pm 4.81$ & $127.15 \pm 23.9$ & $35.84 \pm 3.92$ & $47.57 \pm 4.83$ & $1.07 \pm 0.08$ & $142.08 \pm 49.13$ & $28.17 \pm 7.28$ \\
Twin & $0.41 \pm 0.15$ & $24.42 \pm 2.91$ & $86.98 \pm 6.11$ & $167.1 \pm 36.99$ & $33.12 \pm 2.16$ & $47.62 \pm 2.28$ & $1.08 \pm 0.13$ & $149.18 \pm 28.68$ & $35.71 \pm 4.94$ \\
P-value & 0.376 & 0.377 & 0.378 & 0.395 & 0.565 & 0.993 & 0.930 & 0.905 & 0.419 \\
\hline
\end{tabular}

Explanations: means with varied superscripts in a column are significantly different $(\mathrm{p}<0.05)$. MFW - mean fetal weight; MCRL - mean crown-rump length; MGA - mean gestational age; AST - aspartate aminotransferase; ALT - alanine aminotransferase; $\mathrm{E}_{2}-$ estradiol; $\mathrm{P}_{4}$ - progesterone 
creatinine, estrogen and progesterone concentrations between single pregnancies and twin pregnancies in Red Maradi goats (Tab. 1).

Ovarian biometrics. Twin pregnant Red Maradi goats had significantly higher $(p<0.05)$ left ovarian weights (LOW), average ovarian weight (AOW), left ovarian diameters (LOD) and average ovarian diameter (AOD) compared with single pregnancies. However, the right ovarian weights (ROW) and diameters (ROD) did not differ $(p>0.05)$ between sinlgeton and twin pregnant Red Maradi goats (Fig. 1).

Electrolytes, total protein and glucose. Concentrations of calcium and inorganic phosphates significantly increased $(p<0.05)$ in the single bearing goats compared with the twin bearing goats. Contrarily, sodium, potassium, chloride, total protein and glucose did not significantly vary $(p>0.05)$ between the single bearing and the twin bearing doe-goats (Fig. 2).

Ovarian histomorphology. Using random estimation on the histological pictures of the ovarian sections, it was observed that single bearing mid gestation goats had more primordial follicles nesting the cortical areas of the ovary and fewer antral follicles compared

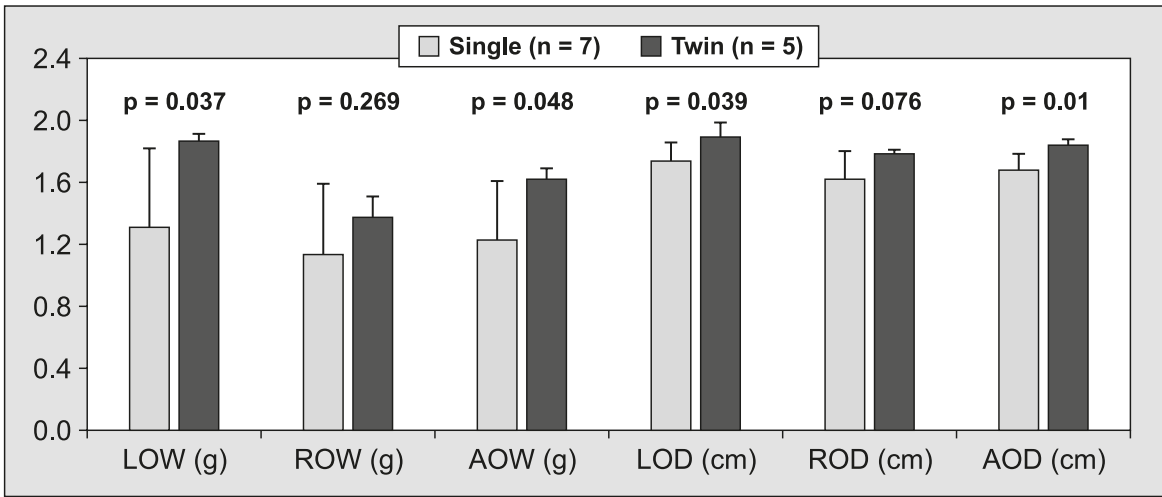

Fig. 1. Ovarian biometrics of twin and single pregnant Red Maradi goats Explanations: left ovarian weight (LOW), right ovarian weight (ROW), average ovarian weight (AOW), left ovarian diameter (LOD), right ovarian diameter (ROD), average ovarian diameter (AOD) of single and twin pregnant Red Maradi goats

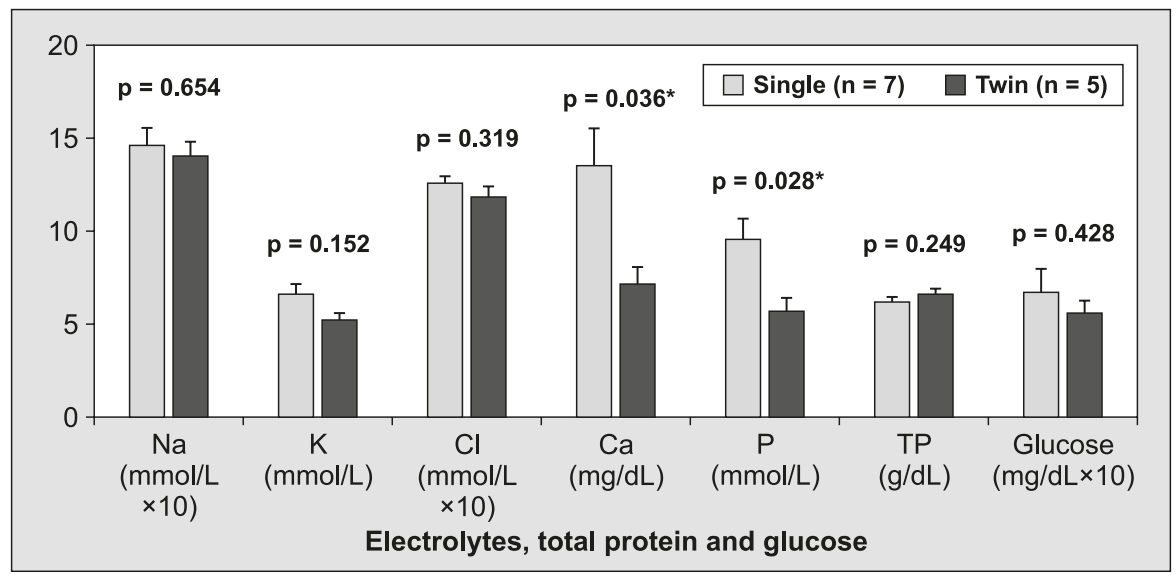

Fig. 2. Serum concentrations of sodium (Na), potassium (K), chloride (Cl), calcium (Ca), phosphorus (P), total protein (TP) and glucose of single and twin pregnant Red Maradi goats with the ovaries from the twin bearing goats (Fig. 3A). On the other hand, the ovarian sections from the twin bearing mid gestation goats had more growing and antral follicles and fewer primordial follicles compared with the single bearing goats (Fig. 3B).

Except for the pathological cases of teratogenicity and other genetic abnornalities, each fetus at a given
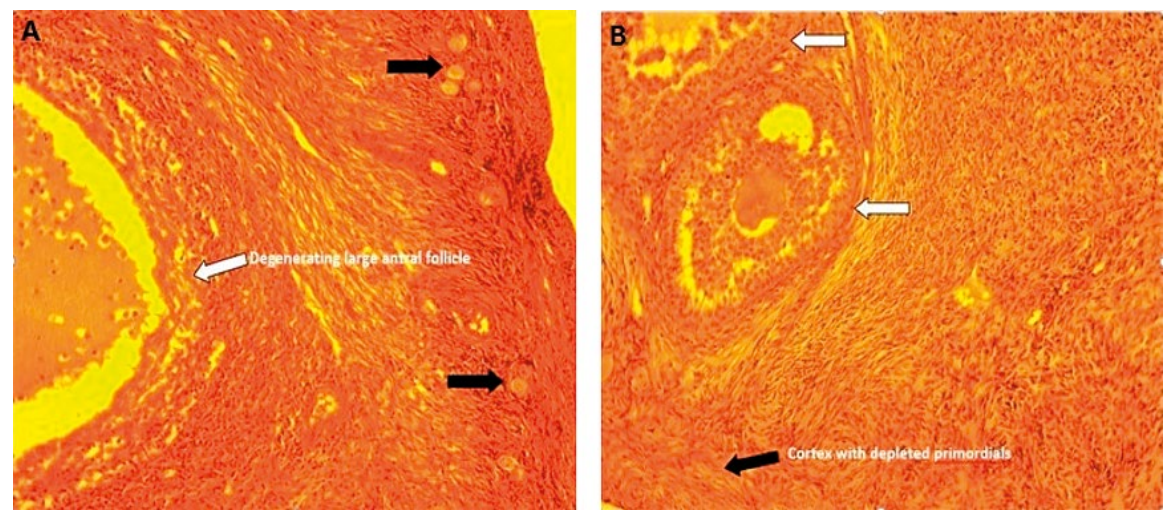

Fig. 3. A - Photomicrograph of the ovaries from singleton Red Maradi goats showing fewer antral follicles (white arrows) and more primordial follicles at the ovarian cortex (black arrows). H\&E stain, $\times 100$. B - Photomicrograph of the ovaries from twin bearing Red Maradi goats showing more antral follicles (white arrows) and cortex with depleted primordial follicles (black arrows). H\&E stain, $\times 100$.

age should have a specified weight and crown-rump length (14), hence the statistical sameness observed in the parameters used for fetal biometrics and determination of gestation age (MFW and MCRL) between single bearing and twin pregnant Red Maradi goats. This also formed the basis on which the comparative analysis of ovarian morphology and serum biochemistry of the single and twin bearing doe-goats.

The left ovarian weights, average ovarian weight, left ovarian diameters and average ovarian diameter were significantly higher in the twin bearing does compared with single pregnancies. However, the right ovarian weights and diameters did not differ between sinlgeton and twin pregnant Red Maradi goats. This result indicates that during pregnancy, the left ovaries were more active than the right ovaries in both single and twin bearing pregnancies. This observations differed significantly from reports in non-pregnant goats that established that the right ovaries were more active with higher weights and diameters than the left ovaries $(2,19,20)$. 
Moreover, caprine ovaries with corpus luteum of pregnancy had higher weight compared with ovaries of similar age and reproductive stage that are devoid of corpus luteum of pregnancy $(2,19)$. The differences observed in the left ovaries of pregnant Red Maradi goats could be attributed to increasing number of ovulations and developing copora lutea in twin pregnant goats when compared with single pregnant goats. This could be attributed to the established fact that the caprine left ovaries contain more ovarian follicles and cumulus oocyte complexes (2) and the tendency of twin/multiple ovulations from the left ovaries is higher thereby contributing to the observed significantly higher left ovarian weights and diameters in the twin bearing does.

The mineral requirements for pregnancy are directly related to the number and size of fetuses $(32,40)$; however, information regarding the maternal management of the mineral metabolism between single and twin pregnancy is not well established (15). The serum concentrations of calcium and inorganic phosphates are significantly higher in the single bearing goats compared with the twin bearing goats, but there was no difference in the concentrations of sodium, potassium and chloride between the single bearing and the twin bearing does. The significant reduction in the maternal serum calcium and phosphorus in the twin bearing goats could be related to the increased utilization of these minerals (calcium and phosphorus) by the twin fetuses in the process of bone formation, leading to lower serum concentrations compared with the single bearing goats. Similar observations were made by Jo et al. (21).

Most biological processes that require energy expenditure, such as muscle contraction, blood coagulation, bone formation and cardiac control, directly need calcium, in addition to phosphorus (40). In pregnant goats, the need for these minerals is further extended because of the developing fetus and additional stress imposed on the pregnant mother (15). The increased need for calcium and phosphorus is handled by apparent increase in the absorption of these minerals from food, without modifying the rate at which they are lost in faeces and urine, and enhanced bone resorption. The clinical implication of this is that twin pregnant goats may require calcium and phosphorus supplementation in the last stages of gestation in order to avoid parturient paresis (24).

No differences were detected in both the maternal serum concentrations of sodium, potassium, chloride. This suggests that the amount of these minerals required for the growth of the fetuses and pregnancy tissues could be sufficiently obtained from diet and optimized by a decrease in endogenous excretion (15). This is consistent with the previous findings, where there was no variation in the potassium, sodium and phosphaates (38).

There was no variation in maternal serum concentrations of urea, creatinine, aspartate aminotransferase (AST), alanine aminotransferase (ALT) and total protein. This could be attributed to the fact that these kidney and liver markers are not usually expressed in significant quantities in the fetuses. They are markers that depict ageing and injury. Previous studies have stated that aspartate transaminase (AST), alanine aminotransferase (ALT) and total protein levels are not affected by pregnancy and the number of developing fetuses $(6,34)$.

Even though progesterone and estrogen concentrations are usually higher in twin pregnancies compared with the singleton pregnancy during the early gestation $(25,36)$, the present study showed no significant difference in these hormone concentrations between the single and twin pregnancies during mid gestation.

The number of corpora lutea which is likely to be more in the twin pregnant goats determines the level of steroids (progesterone and oestrogen) production during pregnancy (31). However, a non-significant increase was observed in the twin pregnant goats in this study. In goats, as opposed to sheep, the corpus luteum is the primary source of progesterone throughout gestation, with little contribution from other steroidogenic tissues like the placenta $(13,42)$. This could be due to a feedback control mechanism as well as mobilization of pregnancy steroids from other steroidogenic tissues, like the placenta through the induction of 3-beta dehydrogenase, thereby balancing out the effect. The developing fetus is contained in the placenta, a membrane that facilitates the exchange between the maternal and fetal circulation. In goats and sheep, the placenta experiences the most rapid growth between 70 to 90 days of gestation (10), which corresponds to the gestational age range for the present study.

The presence of more primordial follicles and fewer antral follicles in the ovaries of the singletons when compared with the ovaries of twin pregnancies which had fewer primordial follicles and more antral follicles implies that the rate of follicle recruitment in single pregnancies was lower in relation to twin pregnancies. Twinning in goats as well as other domestic ruminants has been reported to be genetically determined through the induction of insulin-like growth factor-I (IGF-I) and insulin-like growth factor binding protein-3 (IGFBP-3), leading to an increase in ovulation rate (26). These growth factors initiate increased initial recruitment of primordial follicles which leads to an increase in folliculogenesis and ovulation rate experienced in twin pregnancies. Also, the IGF-I gene influences reproductive process by stimulating ovarian activity (28), and regulates female reproductive hormones (22). This means that the IGF-I stimulates the anterior pituitary for secretion of $\mathrm{LH}$ which regulates reproductive activity in mammals (9). It has also been documented that mutation in the promoter region of the genes related to litter size may affect ovulation rate in goats, resulting in a corresponding change in prolificacy in small ruminants $(3,16)$.

In conclusion, based on our results we can suggest that twin pregnancy, which could be genetically pro- 
grammed, has the tendency to affect ovarian follicles development, ovarian morphometrics and calcium metabolism in mid gestation in Red Maradi goats.

\section{References}

1. Al-baggal H. A. R., Al-Dahash S. Y. A., Alwan A. F.: Microscopic study of the female genital system of Iranian goats. Small Rumin Res. 1993, 9, 341-346, doi: $10.15835 / \mathrm{nsb} 9110012$

2. Alsafy M. A. M., El-Shahat K. H.: Morphological Evaluation of Ovary in Relation to Recovery, Quality of Oocytes and Steroid Production in Sheep. J. Appl. Biol. Sci. 2011, 5 (3), 27-31, doi: 10.1016/j.eurox.2019.100047.

3. An X. P., Hou J. X., Lei Y. N., Gao T. Y., Cao B. Y.: Polymorphism and DNA methylation in the promoter modulate KISS1 gene expression and are associated with litter size in goats. Anim. Reprod. Sci. 2015, 155, 36-41, doi: 10.1016 j.anireprosci.2015.01.013.

4. Arfuso F., Rizzo M., Giannetto C., Giudice E., Fazio F., Piccione G.: Age related changes of serum mitochondrial uncoupling 1 , rumen and rectal temperature in goats. J. Thermal. Biol. 2016, 59, 47-51, doi: 10.1016/j.jtherbio.2016.05.002.

5. Bancroft J. O., Stevens M.: Theory and practice of histological technique. Churchil Livingstone Edinburgh 2002, pp 16-64, doi: 10.1016/c2015-0-00143-5.

6. Carter J.: Liver function in normal pregnancy. Aust. NZ J. Obstet. Gynaecol. 1990, 30, 296-302, doi: 10.1111/j.1479-828x.1990.tb02014.x.

7. Cepeda-Palacios R., Fuente-Gómez M. G., Ramirez-Orduna J. M., GarciaAlvarez A., Llinas-Cervantes X., Angulo C.: Effects of pregnancy and postkidding stages on hemato-chemical parameters in cross-bred goats. J. Appl. Anim. Res. 2018, 46 (1), 269-273, doi: 10.1080/09712119.2017.1295970.

8. Cuckle H.: Prenatal Screening Using Maternal Markers. J. Clin. Med. 2014, 3 (2), 504-520, doi: 10.3390/jcm3020504.

9. Denley A., Cosgrove L. J., Booker G. W., Booker G. W., Wallace J. C., Forbes $B$. E.: Molecular interactions of the IGF system. Cytokine Growth Factor Rev. 2005, 16, 421-439, doi: 10.1016/j.cytogfr.2005.04.004.

10. Doize F., Vaillancourt D., Carabin H., Belanger D.: Determination of gestational age in sheep and goats using transrectal ultrasonographic measurement of placentomes. Theriogenology 1997, 48 (3), 449-460, doi: 10.1016/s0093691x(97)00254-9.

11. Epstein H.: The Origin of Domestic Animals of Africa. Volume I, Africana Publishing Corporation, New York 1971, pp 236-293, doi: 10.1017/ s1014233900000651.

12. Utaaker K. S., Chaudhary S., Kifleyohannes T., Robertson L. J.: Global goat Is the expanding goat population an important reservoir of Cryptosporidium? Front Vet. Sci. 2021, 8, 648500, doi: 10.3389/fvets.2021.648500.

13. Flint A. P. F., Burton R. D., Heap R. B.: Sources of progesterone during gestation in Barbary sheep (Ammotraguslervia). J. Endocrinol. 1983, 98 (2), 283-288, doi: 10.1677/joe.0.0980283.

14. Gabr G. A., Soliman G. A., Saeedan A. S., Al-Kahtani A. A., Ali B. E.: Teratogenic Effects in Rat Fetuses Subjected to the Concurrent in utero Exposure to Emamectin Benzoate Insecticide. Pak. J. Biol. Sci. 2015, 18 (7), 333-340, doi: 10.3923/pjbs.2015.333.340

15. Härter C. J., Castagnino D. S., Rivera A. R., Lima L. D., Silva H. G. O., Mendonca A. N., Bonfim G. F., Liesegang A., St-Pierre N., Teixeira I. A. M. A.: Minera Metabolism in Singleton and Twin-pregnant Dairy Goats. Asian Austr. J. Anim. Sci. 2015, 28 (1), 37-49, doi: 10.5713/ajas.14.0214.

16. He J. N., Zhang B. Y., Chu M. X., Wang P. Q., Feng T., Cao G. L., Di R., Fang L. Huang D. W., Tang Q. Q., Li N.: Polymorphism of insulin-like growth factor 1 gene and its association with litter size in Small Tail Han sheep. Mol. Biol Reprod. 2012, 39, 9801-9807, doi: 10.1007/s11033-012-1846-y.

17. Igado O. O., Ajala O. O., Oyeyemi M. O.: Investigation into the Hematological and Liver Enzyme Changes at Different Stages of Gestation in the West African Dwarf Goat (Capra hircus L.). Int. J. Anim. Vet. Adv. 2011, 3 (5), 277-281, doi: 10.1007/s00580-013-1845-y.

18. Ipsa E., Cruzat V. F., Kagize J. N., Yovich J. L., Keane K. N.: Growth Hormone and Insulin-Like Growth Factor Action in Reproductive Tissues. Front Endocrinol. 2019, 10, 777, doi: 10.3389/fendo.2019.00777.

19. Islam M. R., Khandoker M. A., Afroz S., Rahman M. G. M., Khan R. I.: Qualitative and quantitative analysis of goat ovaries, follicles and oocytes in view of in vitro production of embryos. J. Zhejiang Univ. Sci. B. 2007, 8 (7), 465-469, doi: 10.1631/jzus.2007.B0465.

20. Jaji A. Z., Buduwara R. A., Akanmu A. L., Zachariah M., Luka J., Gambo B. Pregnancy related biometric changes in the ovaries and uterus of the Sahelian goat. Sokoto J. Vet. Sci. 2012, 10 (1), 17-21, doi: 10.4314/sokjvs.v10i1.4

21. Jo B. W., Shim Y. J., Choi J. H., Kim J. S., Lee H. J., Kim H. S.: Formula fed twin infants with recurrent hypocalcemic seizures with vitamin D deficient rickets and hyperphosphatemia. Ann. Pediatr. Endocrinol. Metab. 2015, 20 (2), 102-105, doi: 10.6065/apem.2015.20.2.102

22. Jones J. I., Clemmons D. R.: Insulin-like growth factors and their binding proteins: biological actions. Endocr. Rev. 1995, 16, 3-34, doi: 10.1210/edrv-16-1-3.
23. Kawu M., Eduvie L., Lakpini C., Ayo J.: Peripheral serum progesterone profile in multiparous Nigerian Red Sokoto goats between day one and 30 postpartum. Vet. Arhiv. 2007, 77 (6), 543-550, https://hrcak.srce.hr/24359.

24. Kojouri G. H. A.: Parturient paresis and its relationship with hypophosphatemia. Acta Vet. Scand. 2003, 44 (1), 126, doi: 10.1186/1751-0147-44-S1-P126.

25. Kuijper E. A. M., Twisk J. W. R., Korsen T., Caanen M. R., Kushnir M. M., Rockwood A. L., Meikle A. W., Hompes P. G., Wit J. M., Lambalk C. B.: Midpregnancy, perinatal, and neonatal reproductive endocrinology: a prospective cohort study in twins and singleton control subjects. Fertil. Steril. 2015, 104 (6), 1527-1534, doi: 10.1016/j.fertnstert.2015.08.016

26. Lan X. Y., Pan C. Y., Chen H., Zhao M., Li J. Y., Yu J., Zhang C. L., Lei C. Z. Hua L. S., Yang X. B.: The novel SNPs of the IGFBP3 gene and their associations with litter size and weight traits in goat (Brief report). Arch. Tierzucht. 2007, 50, 223-224, doi: 10.5194/aab-50-223-2007.

27. Ling Y. H., Ren C. H., Guo X. F., Xu L. N., Huang Y. F., Luo J. C., Zhang Y. H., Zhang $X$. R., Zhang $Z$. J.: Identification and characterization of microRNAs in the ovaries of multiple and uniparous goats (Capra hircus) during follicular phase. BMC Genom. 2014, 15 (1), 339, doi: 10.1186/1471-2164-15-339.

28. Lucy M. C.: Regulation of ovarian follicular growth by somatotropin and insulinlike growth factors in cattle. J. Dairy Sci. 2000, 83, 1635-1647, doi: 10.3168 jds.S0022-0302(00)75032-6.

29. Mackie F. L., Whittle R., Morris R. K., Hyett J., Riley R. D., Kliby M. D.: Firs trimester ultrasound measurements and maternal serum biomarkers as prognostic factors in monochorionic twins: a cohort study. Diagn. Progn. Res. 2019, 3, 9, doi: 10.1186/s41512-019-0054-9.

30. Mahmood Z. K. H., Jesse F. F., Saharee A. A., Jasni S., Yusoff R., Wahid H. Assessment of blood changes post-challenge with Corynebacterium pseudotuberculosis and its exotoxin (phospholipase D): A comprehensive study in goat. Vet. World 2015, 8, 1105-1117, doi: 10.14202/vetworld.2015.1105-1117.

31. Miranda-Moura M. T. M., Oliveira G. B., Peixoto G. C. X., Pessoa P. C., Maia M. S., Moura C. E. B., Oliveira M. F.: Morphology and vascularization of the corpus luteum of Peccaries (Pecaritajacu, Linnaeus, 1758) throughout the estrous cycle. Arq. Bras. Med. Vet. Zootec. 2016, 68 (1), 87-96, doi: 10.1590/1678 4162-8486

32. National Research Council. Nutrient Requirements of Small Ruminants Sheep Goats, Cervids and New World Camelids. National Academy Press; Washington, DC, USA 2007, pp. 384, doi: 10.1590/s1516-35982008001300020.

33. Okoye C. N., Abiaezute C. N., Ekere O. S.: Some Uterine and Ovarian Biometric Changes in Pregnant Maradi Female Goats (Capra aegagrushircus L.). Not. Sci. Biol. 2017, 9 (1), 54-58, doi: 10.15835/nsb9110012.

34. Pasciu V., Baralla E., Nieddu M., Succu S., Porcu C., Leoni G. G., Sechi P., Bombo G. C., Berlinuer F.: Commercial human kits' applicability for the determination of biochemical parameters in sheep plasma. J. Vet. Med. Sci. 2019, 81 (2), 294-297, doi: 10.1292/jvms.18-0356.

35. Piccione G., Caola G., Giannetto C., Grasso F., Calanni R. S., Zumbo A., Pennisi P.: Selected biochemical serum parameters in ewes during pregnancy, post-parturition, lactation and dry period. Anim. Sci. Pap. Rep. 2009, 27, 321 330, doi: 10.1007/s00580-021-03232-1.

36. Póvoa A., Xavier P., Matias A., Blickstein I.: First trimester $\beta$-hCG and estradio levels in singleton and twin pregnancies after assisted reproduction. J. Perinat. Med. 2017, 46 (8), 853-856, doi: 10.1515/jpm-2017-0132.

37. Richardson C., Herbert C. N., Terlecki S.: Estimation of the developmental age of the ovine fetuses and lambs. Vet. Rec. 1976, 99, 22-26, doi: 10.1136/ vr.99.2. 22.

38. Shukla P., Rajput R., Kumar R., Verma M.: Studies on Biochemical Constituents of Goat Allantoic Fluid during Different Stages of Gestation in Gaddi Sheep. Indian J. Anim. Res. 2019, 53 (2), 178-180, doi: 10.18805/ijar.B-3477.

39. Soma-Pillay P., Nelson-Piercy C., Tolppanen H., Mebazaa A.: Physiological changes in pregnancy. Cardiovasc. J. Afri. 2016, 27 (2), 89-94, doi: 10.5830/ CVJA-2016-021.

40. Suttle N. F: The mineral nutrition of livestock. $4^{\text {th }}$ ed. CABI International Wallingford UK 2010, pp. 587, doi: 10.1079/9781845934729.0000.

41. Wilson R. T.: Small ruminant production and the small ruminant genetic resource in tropical Africa. Illustrated ed. Food \& Agriculture Organization 1991, pp. 231, doi: 10.5367/000000003101294451

42. Yahi D., Ojo N. A., Mshelia G. D.: Influence of Dexamethasone on Some Reproductive Hormones and Uterine Progesterone Receptor Localization in Pregnant Yankasa Sheep in Semiarid Zones of Nigeria. J. Vet. Med. 2017, 9514861, doi: 10.1155/2017/9514861.

43. Zulkifli I., Norbaiyah B., Cheah Y. W., Farjam A. S., Sazilli A. Q., Rajion M. A.: Physiological responses in goats subjected to Road Transportation under the hot, humid tropical conditions. Int. J. Agric. Biol. 2010, 12, 840-844, doi: 10.5455/ javar.2016.c129.

Corresponding author: Dr. Hillary Emeka Ugwuanyi, Department of Veterinary Physiology and Pharmacology, University of Nigeria, Nsukka, 410001 Nigeria; e-mail: emeka.ugwuanyi@unn.edu.ng 